\title{
Intratracheal Seal Disc: A Novel Tracheostoma Closure Device
}

\author{
Karen J Christiansen RN, Niels Moeslund, Henrik Lauridsen PhD, Louise Devantier MD, \\ Marianne C Rohde PhD, Benedict Kjærgaard MD, and Michael Pedersen PhD
}

\begin{abstract}
BACKGROUND: Tracheostomy decannulation is accompanied by several clinical concerns due to air leakage. In this study, we introduced a novel tracheostoma closure device that facilitates the use of noninvasive ventilation, improvement of pulmonary function, and vocalization in the newly decannulated patient. The biosafety and feasibility of the device were evaluated in an animal model. METHODS: Five Danish Landrace pigs were subjected to tracheostomy followed by decannulation and insertion of the tracheostoma closure device. Correct placement of the device was ensured by flexible tracheoscopy. The device consisted of an intratracheal silicone seal disc fixated by a cord through the stoma to an external part. At day 14, computed tomography (CT) was performed before the device was extracted. With the pulling of a cord, the disc unraveled into a thin thread and was extracted through the stoma. At day 21, CT was repeated before euthanasia. The trachea and epidermis were excised en bloc for histopathological evaluation. RESULTS: Insertion and correct placement of the disc was unproblematic in all animals. CT at day 14 confirmed a clear airway, appropriate placement of the disc, and full closure of the tracheostoma. Extraction was successful in one animal but complicated in the remaining animals. There was histological evidence of healing after the foreign body placement. CONCLUSIONS: The study demonstrated that the tracheostoma closure device is feasible and biosafe in a porcine animal model, but the design and quality of the materials need to be improved before clinical trials. Key words: tracheostomy; decannulation; computed tomography; histology; animal model; device. [Respir Care 2017;62(7):970-977. (C) 2017 Daedalus Enterprises]
\end{abstract}

\section{Introduction}

Tracheotomy is a common procedure, and the number of patients undergoing temporary tracheostomy is increas-

\footnotetext{
Ms Christiansen, Mr Moeslund, Dr Lauridsen, Dr Devantier, and Dr Pedersen are affiliated with the Comparative Medicine Laboratory, Department of Clinical Medicine, and Dr Rohde is affiliated with the Department of Forensic Medicine, Aarhus University, Aarhus, Denmark. Ms Christiansen is also affiliated with the Department of Cardiology, Aarhus University Hospital, Aarhus, Denmark. Dr Devantier is affiliated with the Department of Otorhinolaryngology, Head and Neck Surgery, Aarhus University Hospital, Aarhus, Denmark. Dr Rohde is affiliated with the Department of Forensic Medicine, Aarhus University, Aarhus, Denmark. Dr Kjærgaard is affiliated with the Department of Clinical Medicine, Aarhus University, Aarhus, Denmark and the Department of Thoracic Surgery, Aalborg University Hospital, Aalborg, Denmark.
}

Ms Christiansen and Mr Moeslund are co-first authors.

This work was supported by the A.P. Møller og Hustru Chastine McKinney Møllers Fond til almene Formaal. Ms Christiansen has disclosed an international patent application, number PCT/EP2015/064892. The other authors have disclosed no conflicts of interest. ing due to aging populations and comorbidity. ${ }^{1-3}$ An international survey reported that $24 \%$ of mechanically ventilated patients in intensive care units were ventilated through a tracheostomy tube. ${ }^{4}$ Tracheostomy decannulation is required once the underlying indication for the tracheostomy has resolved. ${ }^{5-9}$ Removal of the tracheostomy tube leaves an artificial hole in the patient's airway, which is covered with occlusive dressing or gauze bandage. Patients are instructed to apply pressure over the dressing with their fingers when talking or coughing to reduce air leakage.

\footnotetext{
Supplementary material related to this paper is available at http:// www.rcjournal.com.

Correspondence: Karen J Christiansen RN, Comparative Medicine Laboratory, Department of Clinical Medicine, Aarhus University, Palle Juul-Jensens Boulevard 99, 8200 Aarhus N, Denmark. E-mail: karen@clin.au.dk.
}

DOI: $10.4187 /$ respcare. 05301 


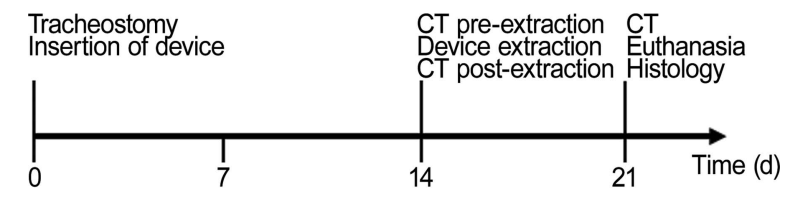

Fig. 1. Timing of study. CT = computed tomography.

Air leakage through the tracheostomy compromises vocalization, throat clearing, deep sighs, and cough competence. ${ }^{10,11}$ Tracheostomy dressing tends to loosen due to air leakage, and frequent changes are indicated when excessive amounts of secretion pool from the tracheostoma. Secretions and the continuous flow of air may delay and even hinder proper closure of the tracheostoma. In some patients delayed closure of the tracheostoma induces development of a tracheocutaneous fistula requiring surgical closure. We believe that intratracheal sealing of a tracheostomy will optimize lung function and promote wound healing in the newly decannulated tracheostomy patient.

This study evaluated the feasibility of intratracheal sealing using a novel device, and the purposes were: (1) to evaluate whether an intratracheal closure device could be inserted via a tracheostomy tube; (2) to evaluate any acute adverse effects due to the foreign material in the trachea; (3) to investigate the tension mechanism, design, and material; and (4) to evaluate its impact on trachea and pretracheal tissue.

\section{Methods}

\section{Study Design}

Five Danish Landrace pigs ( $\sim 60 \mathrm{~kg}$ ) were used in this study. The animals underwent treatment with the sealing device for 2 weeks and were subsequently observed for 1 week (Fig. 1).

\section{Device Design}

The device was fabricated in 2 parts: an intratracheal closing device consisting of a silicone seal disc and an extratracheal fastening device consisting of an outer tension and fastening housing. The silicone disc had a diameter of $26.5 \mathrm{~mm}$ and was cut in a spiral pattern to provoke a spiral line of weakness for extraction. The silicone composition of the disc permitted folding on insertion through the tracheostomy tube, and subsequent unfolding on entry into the intratracheal space. Retraction of the device and tracheostomy tube formed a secure internal seal. Tension was maintained between the internal disc and the external cover via a spring tethering system. This allowed secure placement while allowing removal in the event of emergency. A peel thread was attached to the outer end of the

\section{QUICK LOOK}

\section{Current knowledge}

Tracheostomy decannulation is an important step in rehabilitating the critically ill patient toward independent breathing. After decannulation, wound healing is impaired by a variable flow of air and by secretions until the canal has closed. Decannulation is associated with a risk of respiratory failure.

\section{What this paper contributes to our knowledge}

Treatment with an intratracheal seal disc was feasible in an animal model. The device was inserted through a percutaneous dilatational tracheostomy and fixated by a flexible tensioning system. All animals tolerated the device showing no signs of airway obstruction and the tracheas were intact at the end of the study.

spiral and passed through the center to enable peeling of the disc to a cord. A fastening thread was attached at several points within the disc in a pattern not interfering with the peeling (Fig. 2). The thread was connected to a spring in the outer housing for sufficient and continuous tension.

The outer housing consisted of 2 parts: a plate with tethering points for the peeling and the tension threads and a tension spring and a hole lined with polytetrafluoroethylene to minimize friction where the threads passed through the hole. A lid covered the internal housing parts (Fig. 3).

A spring tethering system was used for safety and comfort to ensure that the seal remained in position during body movement or during slight elevation of the housing part for veterinary wound inspection and care. The spring was adjusted so that the force exerted by the seal disc would not exceed $25 \mathrm{~mm} \mathrm{Hg.}{ }^{12}$

The lengths of the threads in the outer housing was adjusted to allow the housing to be lifted approximately $2 \mathrm{~cm}$ off the skin without tensioning the peeling thread. The seal disc was designed for extraction through the tracheostoma canal if the housing was subjected to extensive force.

\section{Animal Handling}

The experimental procedures were in accordance with national Danish legislation on the care and use of laboratory animals. The study was approved by the Danish Animal Experiment Inspectorate (approval 2014-15-020100265).

We used a porcine animal model because pigs' tracheal dimensions are comparable with those of adult humans. 


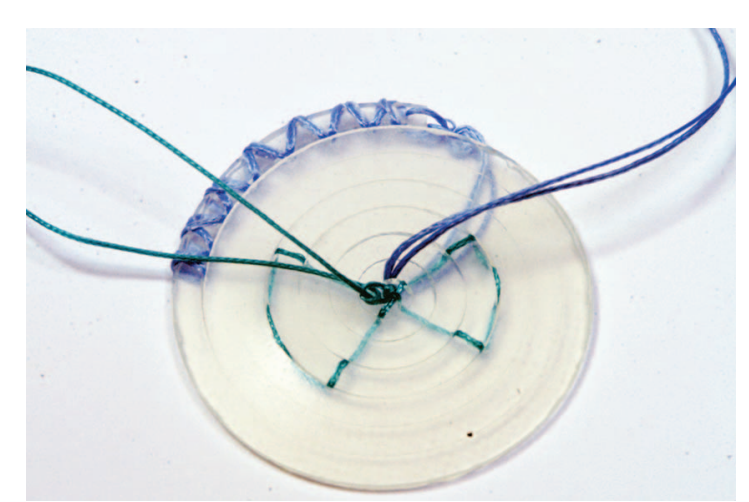

Fig. 2. The silicone seal with a predetermined line of weakness. Two different threads are attached for tensioning and unraveling function, respectively.

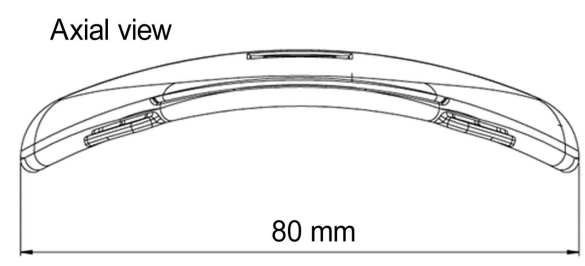

Sagittal view
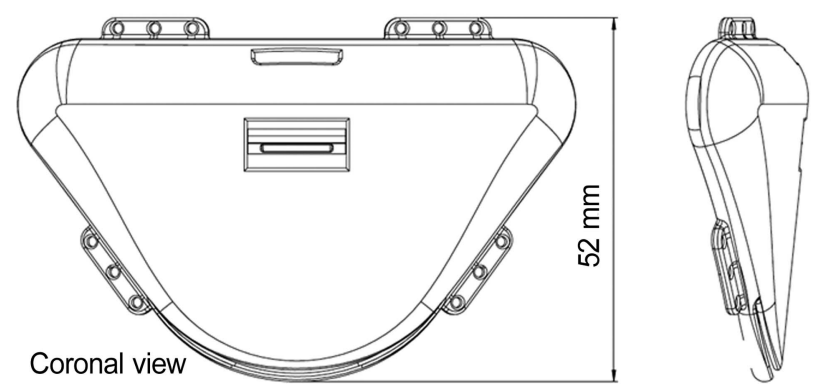

Fig. 3. Outer housing comprising attachment means for the silicone threads.

The animals were anesthetized with repeated intramuscular injections of Zoletil Vet 50, a mixture of ketamine $(6.25 \mathrm{mg} / \mathrm{mL})$, tiletamine $(6.25 \mathrm{mg} / \mathrm{mL})$, benzodiazepine (6.25 mg/mL), synthetic opioid (butorphanol) $(1.25 \mathrm{mg} / \mathrm{mL})$, and xylazin $(6.5 \mathrm{mg} / \mathrm{mL})$. After the invasive procedure, the animal received an intramuscular injection of flunixin $(50 \mathrm{mg} / \mathrm{mL}, 2.5 \mathrm{~mL})$ and buprenorphin $(0.3 \mathrm{mg} / \mathrm{mL}$, $3 \mathrm{~mL}$ ) at 8 -h intervals for $3 \mathrm{~d}$.

The trachea was intubated with a cuffed 8-mm internal diameter tube, and the lungs were ventilated mechanically using a ventilator (S5 Advance, Datex-Ohmeda S5, Helsinki, Finland) with an $8-10 \mathrm{~mL} / \mathrm{kg}$ tidal volume and a PEEP of $5 \mathrm{~cm} \mathrm{H}_{2} \mathrm{O}$. The frequency and tidal volume were continuously adjusted to maintain $\mathrm{P}_{\mathrm{aCO}_{2}}$ between 33 and $42 \mathrm{~mm} \mathrm{Hg}$. The $\mathrm{F}_{\mathrm{IO}_{2}}$ was set to $60 \%$. Before the invasive procedure, a long-acting antibiotic, Curamox $(1 \mathrm{~g})$, was administered intramuscularly. A percutaneous tracheostomy introducer set (Ciaglia Blue Rhino tracheostomy in- troducer set, Cook Medical, Bloomington, Indiana) was used, and an 8-mm inner diameter tracheostomy tube with an outer diameter of $11.9 \mathrm{~mm}$ (Portex Blue Line Ultra, Smith Medical, Kent, United Kingdom) was introduced into the trachea under bronchoscopy guidance (aScope 3, AMBU, Copenhagen, Denmark). The oral tube was withdrawn to a level just beneath the vocal cords, and ventilation was performed using the tracheostomy tube whenever indicated. After $15 \mathrm{~min}$, the tracheostomy tube was used to insert the intratracheal seal disc into the trachea, the tracheostomy tube was removed, and the cord attached to the disc was connected to the external device with an automatic tensioner. The extratracheal fastening device was sutured to the skin, and the neck was dressed with circular self-adhesive bandages applied without tension. The position of the internal disc was controlled by tracheoscopy (see supplemental video at www.rcjournal.com). The translaryngeal tracheal tube was removed after weaning from anesthesia, and the pigs were transferred to a stable facility, where veterinary care and observation were managed by trained animal technicians. Feeding troughs were changed to flat bowls to minimize mechanical force toward the front neck.

After 2 weeks, the animal was reanesthetized to a level inducing sleep with preserved ventilation. Computed tomography (CT) (time point: seal in place) of trachea was performed to determine the position of the disc. The disc was then peeled out $(0 \mathrm{~d}$ post-extraction $)$. The pig was observed for another week in the animal facility. Next, the animal was reanesthetized, followed by another CT examination ( $7 \mathrm{~d}$ post-extraction). Finally, the animal was sacrificed, and histological specimens were obtained for analysis.

\section{CT}

CT was employed to qualitatively evaluate device placement and to quantify any tracheal stenosis or dilation during and after treatment using a clinical system (Siemens Somatom Definition, Siemens Medical Solutions, Forchheim, Germany) with the following parameters: field-ofview from snout to diaphragm, $0.6 \times 0.6 \times 0.6 \mathrm{~mm}^{3}$ voxel size; $120 \mathrm{kVp} ; 200 \mathrm{~mA}$. This resulted in an acquisition time of 90 s. The built-in (Syngo CT 2012B software) B45s convolution kernel was used to reconstruct the CT images. The subsequent analysis was performed with the Amira software (FEI, Hillsboro, Oregon).

\section{Histology}

Areas around the tracheostomy and the seal were removed postmortem en bloc and formalin-fixed immediately after removal, and multiple cross sections in the area of the tracheostomy were made with a 5-mm interval, 


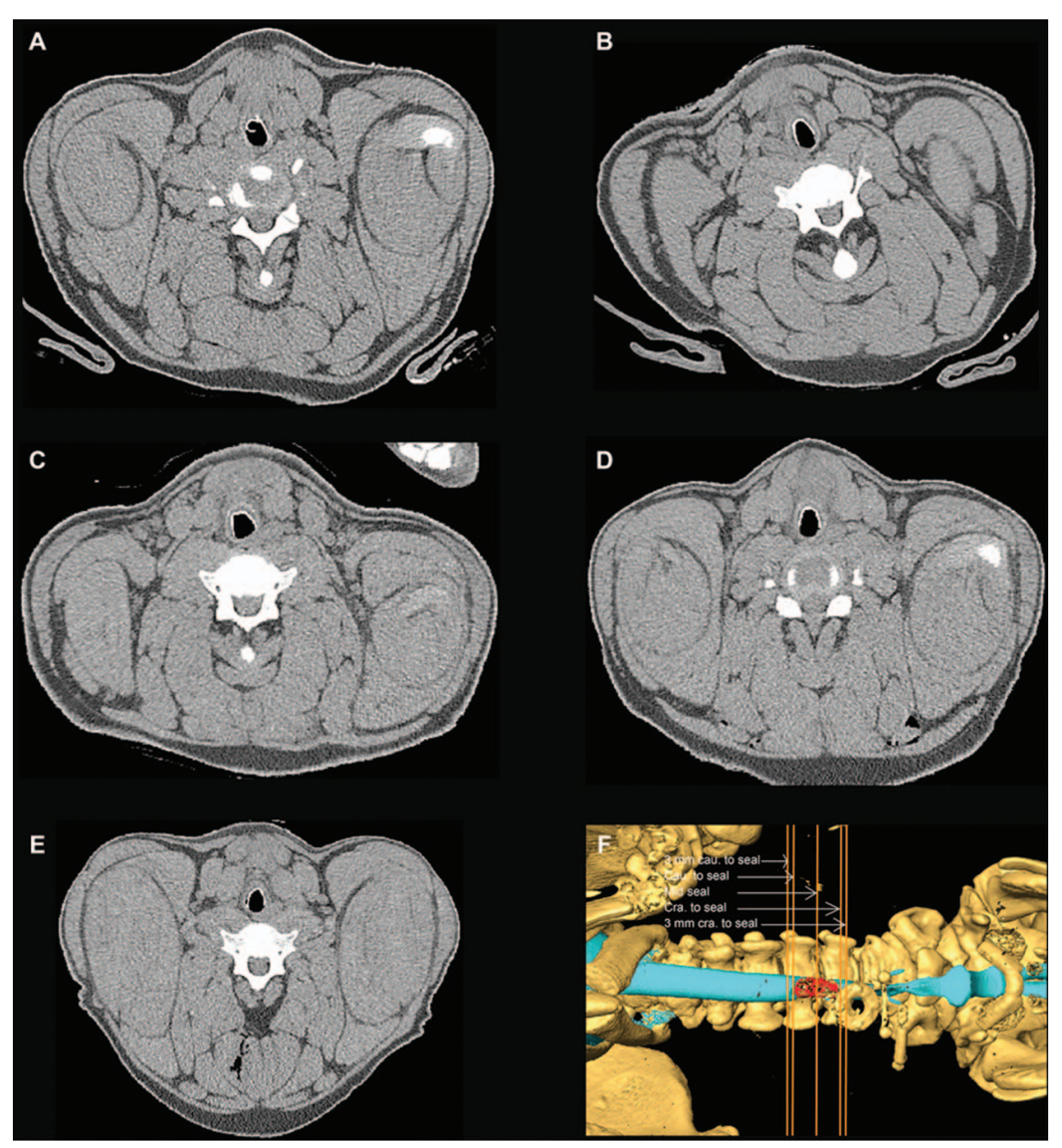

Fig. 4. Transversal cross section of the 5 pigs included in the study at the level of the tracheal seal. In one pig, the tracheal seal $(A)$ was slightly curved, whereas the remaining seals $(B-E)$ were flush with the inner lining of the trachea. F: Surface reconstruction of the skeleton, airways, and tracheal seal in one of the pigs. Lines indicate the cross sections applied to measure cross-sectional area in Table 1. Cau $=$ caudal, cra $=$ cranial.

allowing inspection for inflammation, necrosis, and foreign bodies. For microscopic evaluation, cross sections were sampled from the superficial, middle, and profound areas (slice thickness 3-3.5 $\mu \mathrm{m}$ ). The following stains were used in the microscopic evaluation of the tissue: hematoxylin and eosin, routine stain for tissue and cell evaluation; elastic van Gieson for elastic fibers; and Masson's trichrome, a 3-color staining suited for distinguishing cells from the surrounding connective tissue. Furthermore, Perl's' Prussian blue was used for ferric iron deposits in tissue.

\section{Results}

\section{Animal Behavior and Device Management}

Insertion and intratracheal placement of the seal through the 8-mm inner diameter tube was successful. The animals showed no signs of airway obstruction during the 3 weeks of observation; in one animal, 2 episodes of transitory cough were reported. The animals showed no signs of pain or disability assessed from normal behavior and appetite. The tension between the seal and fastening device was sufficient to keep the seal in place. In one animal, the sealing disc was completely extracted during the removal procedure, and in 4 animals, the disc broke during the peeling procedure and left small pieces of silicone in the pretracheal tissue (see the supplementary materials at http:// www.rcjournal.com). One disc could not be extracted through the tracheostoma canal and was removed endoscopically.

\section{CT}

CT revealed a fully closed tracheostoma canal in all animals at 2 weeks after tracheostomy. The tracheal seal was flush with the inner lining of the trachea in all but one animal (Fig. 4). As expected, the tracheal seal took up 
Intratracheal Seal Disc in a Porcine Model

Table 1. Cross-Sectional Area of Tracheal Lumen at 5 Points Associated With the Tracheal Seal

\begin{tabular}{|c|c|c|c|c|c|c|}
\hline Pig Number & Time Point & $\begin{array}{l}\text { Mid-Seal, } \\
\text { CSA }\left(\mathrm{mm}^{2}\right)\end{array}$ & $\mathrm{Cra}, \mathrm{CSA}\left(\mathrm{mm}^{2}\right)$ & $\begin{array}{l}3 \mathrm{~mm} \mathrm{Cra}, \\
\mathrm{CSA}\left(\mathrm{mm}^{2}\right)\end{array}$ & $\mathrm{Cau}, \mathrm{CSA}\left(\mathrm{mm}^{2}\right)$ & $\begin{array}{l}3 \mathrm{~mm} \mathrm{Cau}, \\
\mathrm{CSA}\left(\mathrm{mm}^{2}\right)\end{array}$ \\
\hline 1 & Seal in place & 84.1 & 135.8 & 148.8 & 83.4 & 107.1 \\
\hline 1 & 0 dpe & 99.0 & 178.0 & 175.3 & 100.7 & 140.4 \\
\hline 1 & 7 dpe & 152.7 & 212.7 & 221.8 & 174.9 & 174.3 \\
\hline 2 & Seal in place & 82.1 & 126.2 & 141.2 & 140.0 & 167.4 \\
\hline 2 & 0 dpe & 114.2 & 112.5 & 109.3 & 152.9 & 170.6 \\
\hline 2 & 7 dpe & 196.3 & 186.9 & 181.8 & 192.4 & 193.0 \\
\hline 3 & Seal in place & 114.9 & 148.9 & 149.5 & 135.0 & 186.1 \\
\hline 3 & 0 dpe & NA & NA & NA & NA & NA \\
\hline 3 & 7 dpe & 172.2 & 129.3 & 100.5 & 192.9 & 196.6 \\
\hline 4 & Seal in place & 122.4 & 114.8 & 133.2 & 180.9 & 191.8 \\
\hline 4 & 0 dpe & NA & NA & NA & NA & NA \\
\hline 4 & 7 dpe & 205.5 & 206.4 & 208.6 & 209.5 & 208.6 \\
\hline 5 & Seal in place & 107.3 & 198.2 & 204.8 & 99.8 & 142.7 \\
\hline 5 & 0 dpe & NA & NA & NA & NA & NA \\
\hline 5 & 7 dpe & 193.9 & 229.0 & 242.8 & 184.0 & 180.2 \\
\hline Mean \pm SD & Seal in place & $102.2 \pm 16.3$ & $144.8 \pm 29.0$ & $155.5 \pm 25.3$ & $127.8 \pm 34.0$ & $159.0 \pm 31.1$ \\
\hline Mean \pm SD & 0 dpe & $106.6 \pm 7.6$ & $145.2 \pm 32.8$ & $142.3 \pm 33.0$ & $126.8 \pm 26.1$ & $155.5 \pm 15.1$ \\
\hline Mean \pm SD & 7 dpe & $184.1 \pm 19.1$ & $192.9 \pm 34.5$ & $191.1 \pm 49.4$ & $190.7 \pm 11.5$ & $190.5 \pm 12.2$ \\
\hline \multicolumn{7}{|c|}{$\begin{array}{l}\text { CSA }=\text { cross-sectional area } \\
\text { dpe }=\text { days post-extraction } \\
\mathrm{Cra}=\text { cranial end of seal } \\
3 \mathrm{~mm} \text { Cra }=3 \mathrm{~mm} \text { cranial to seal } \\
\mathrm{Cau}=\text { caudal end of seal } \\
3 \mathrm{~mm} \text { Cau }=3 \mathrm{~mm} \text { caudal to seal } \\
\mathrm{NA}=\text { not applicable }\end{array}$} \\
\hline
\end{tabular}

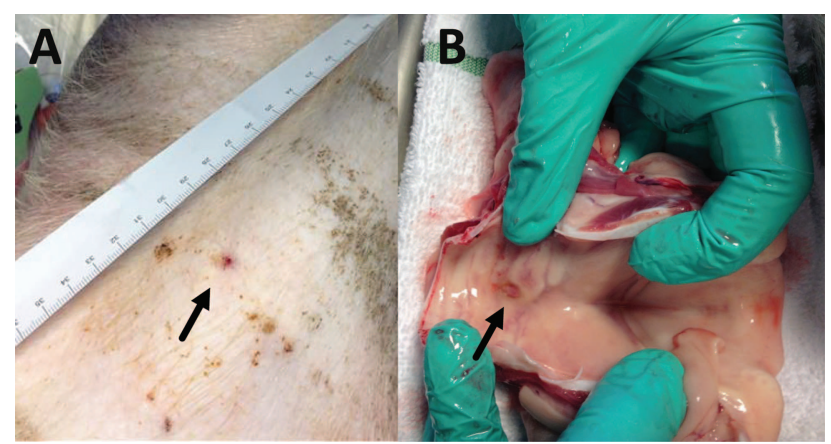

Fig. 5. Inspection of the healed tracheostoma at tissue excision.

some luminal space in the trachea, which reduced the tracheal lumen. However, no signs of stenosis or dilation of trachea were observed (Table 1 and see the supplementary figure at http://www.rcjournal.com).

\section{Histology}

After removal of the intact seal, abnormal macroscopic findings were subtle and almost absent (Fig. 5). Microscopy revealed evidence of healing after foreign body placement, including inflammatory cells, giant cells, and fibroblasts. The affected area was around 1-2 $\mathrm{mm}$ in diameter

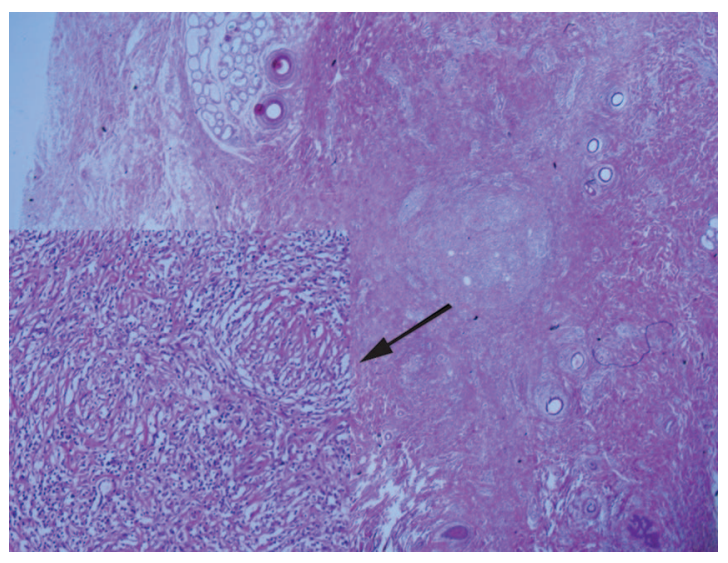

Fig. 6. The superficial layer close to the skin surface in a pig with complete extraction. One week after extraction, the tracheostoma had healed. No signs of acute inflammation were found; only changes following foreign body placement with fibroblast outgrowth and giant cell formation. The arrow points at the enlarged area of the healed tracheostoma. Hematoxylin and eosin stain was used.

in the case with complete removal where the seal did not break off (Fig. 6). The seal broke during extraction in 4 of the pigs. These cases showed abundant signs of inflammation and acute inflammation with neutrophil granulocytes, presumably caused by reactions secondarily to the 


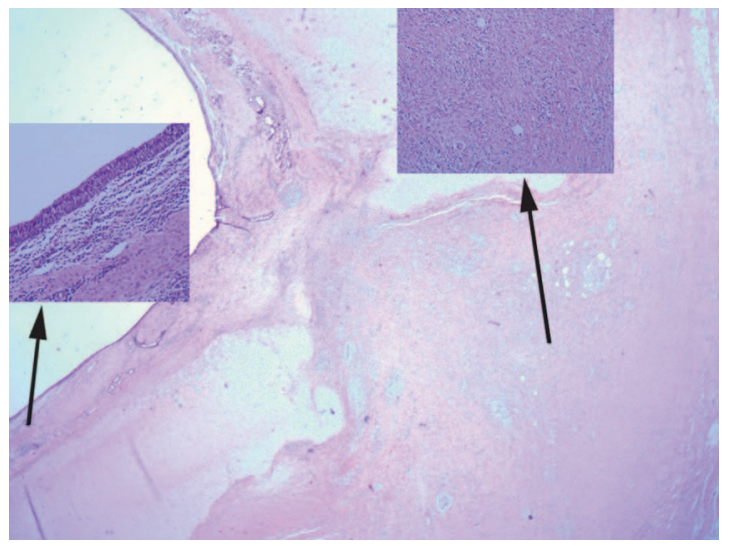

Fig. 7. The endotracheal surface and the area close to the endotracheal surface in a pig where the extraction was complete. One week after extraction, the tracheostoma had healed; the arrow on the right points at the enlarged area of the healed tracheostoma (showing the same area as in Fig 2 from the superficial area). The arrow on the left points at the enlarged area of the intact endotracheal epithelium, where the endotracheal seal was placed. Hematoxylin and eosin stain was used.

broken seal. No pigs showed severe inflammation or abscess. The epithelial layer of the trachea under the seal showed no signs of pressure from the seal macroscopically 1 week after extraction in any pigs. Microscopy revealed absence of necrosis with no signs of damage to the epithelial layer (Fig. 7).

\section{Discussion}

This study demonstrated that the seal was successfully inserted through the tracheostomy tube, the animals tolerated the fixation of the extratracheal fastening device outside the neck, and acute adverse effects were disproved. The tension in the fastening spring was adequate with no signs of seal displacement. Furthermore, histology analysis revealed healed tracheostoma canals with minor traces of inflammation and no signs of epithelial damage under the seal.

We found that tracheostomy management using a temporary intratracheal sealing was feasible in a pig model. The animals tolerated wearing the device, and we observed no changes in animal behavior or respiration. The tensioning system, which was a crucial component, appeared to be appropriate, and we were aware that inadequate tension could have caused displacement of the device with a risk of airway obstruction, and a pressure that was too high might have caused pressure sores and necrosis in the tracheal epithelium or at the skin surface. The diameter of the disc was chosen to fit patients having a tracheostomy tube with an internal diameter of 7-8 millimeters, which will create a canal with a diameter of 10-12 millimeters.
Anesthesia appeared to be adequate, because the animals emerged unharmed from anesthesia in all procedures. We found that experience with proper dosages of Zoletil Vet mixture was crucial to secure appropriate sedation with preserved spontaneous respiration during bandage changes and for $\mathrm{CT}$ procedures.

Daily inspection of the bandages was mandatory to ensure a safe fixation of the external cover. Sedating the animals after 1 week facilitated bandage change, direct external device and skin inspection along the edges of the device, and application of a new circular bandage.

CT was performed to obtain spatial information about the tracheal lumen at the level of the device, and 3-dimensional analysis was useful for interpretation of the placement of the intratracheal closure device. In some cases, we observed that the caudal side of the disc was slightly elevated, possibly due to accumulation of mucus underneath the seal. One week after seal extraction, the tracheostoma canal was completely healed macroscopically and could not be visualized using CT. A macroscopically visible canal was not expected because the animals were not exposed to a permanent tracheostomy. However, there was a risk that the connecting cord could have caused a fistula to develop. Both CT and tissue analysis demonstrated that the animals tolerated this novel intratracheal tracheostoma closure device without developing tracheal stenosis or severe inflammatory reactions.

\section{Study Limitations}

Although the porcine trachea is an excellent preclinical model, ${ }^{13}$ the healing processes in pigs is incompletely characterized compared with that of humans. The animals in this study were approximately $120 \mathrm{~d}$ old at the start of the study, and these relatively young animals may heal faster than adult humans. The depth of pretracheal tissue in the animal models was approximately $5 \mathrm{~cm}$ with the animal in the supine position; the average depth of pretracheal tissue in humans is less than half the depth measured in the animals included in the present study. ${ }^{14}$ This may have an impact on the healing of the canal.

The extraction of the sealing disc was fully successful in one animal only. Thus, the histological analysis was compromised by pieces of silicone left in the pretracheal tissue in 4 animals.

In future studies, it would be interesting to apply the device on a surgically created tracheostoma that is kept open for a prolonged period of time to evaluate the effect of the device on a matured tracheostoma. A preoperative CT baseline analysis of the trachea would be relevant to measure the potential changes of the tracheal lumen following treatment with the closure device. Moreover, histological analysis of the tracheal epithelium by transverse 
section would be relevant to examine in detail any surface damage caused by the seal.

\section{Clinical Perspectives}

A speaking valve is one of the options for oral communication for tracheostomized patients, in whom the speaking valve is placed onto the tracheostomy tube. Before decannulation, the patient should also tolerate a decannulation cap on the tracheostomy tube. Placement of a speaking valve provides many benefits to the patient. First, it allows the patient to create positive endexpiratory pressures; second, it redirects air through the upper airway passing the vocal cords and thereby allows the patient to speak; and third, it enables the clinician to confirm the patency of the patient's upper airway. ${ }^{9,15}$ At decannulation, the speaking valve or the cap is removed along with the tube, and the above-mentioned benefits disappear because air will leak via the open tracheostoma. After decannulation, the tracheostoma is covered by an outer dressing. In clinical practice, the dressings are not airtight unless the patient applies pressure over the dressing using his or her fingers. When the tracheostoma is temporarily closed, vocalization is facilitated by the air deflecting through the upper airway and vocal cords, and in parallel, cough efficacy is enhanced. Due to general clinical fragility, some patients are unable to apply manual pressure over the dressing when needed. We expect that the use of an intratracheal sealing device will address the challenges related to air leakage through the open tracheostoma.

Noninvasive ventilation (NIV) is increasingly used in treatment of respiratory failure. Several trials have shown that the use of NIV advances extubation in the endotracheally intubated patient with prolonged weaning. Application of NIV immediately after extubation is effective in avoiding respiratory failure after extubation, reduces duration of intubation and complication rates, and improves survival. ${ }^{16,17}$ More extensive use of NIV can free up ventilators and other ICU equipment for patients with respiratory insufficiency whose survival depends exclusively on invasive ventilation. ${ }^{18}$ The literature is intensely concerned about respiratory fragility in the phase of tracheostomy tube removal. In the newly decannulated patient, NIV treatment is likely to fail because the system requires an airtight circuit between the mechanical ventilator and the lungs. Patients with an intratracheal sealing of the tracheostomy may benefit from NIV and intermittent CPAP on equal terms with endotracheally intubated patients.

Formation of granulation tissue is acknowledged as an important late complication of tracheostomy. It remains uncertain how granulation tissue will affect the use of a closure device and vice versa. ${ }^{19-21}$ Future studies will show the extent of clinical indications for application of a closure device at decannulation; we expect that the indications will address patients with long-term tracheostomy. Heffner ${ }^{22}$ wrote, "The patients run a marathon toward recovery, and we should not neglect the last mile, which is of equal importance as the first 25 , if they are to cross the finish line."

\section{Conclusions}

This study demonstrated the feasibility of a novel device for intratracheal sealing of a tracheostoma. We demonstrated that an intratracheal seal disc could be inserted through a tracheostomy tube and that the fastening device placed on the neck was tolerated in an animal model. We also demonstrated that the device could be worn with no adverse effect on breathing patterns. Weaknesses in the design of the existing prototype were revealed during the extraction procedure, which contributed with knowledge that may assist further development of the product. After treatment with the closure device, we found that the tracheostomy canal had healed. Macroscopically, we confirmed that the healed wound were flush with the ventral wall of the trachea. Tracheal stenosis and dilation were disproved by CT. However, additional studies are needed to evaluate whether the closure device is beneficial for the healing of tracheostoma canals.

\section{ACKNOWLEDGMENTS}

We thank Professor Jens Christian Djurhuus (Department of Clinical Medicine, Aarhus University) for scientific supervision in study design.

\section{REFERENCES}

1. Santus P, Gramegna A, Radovanovic D, Raccanelli R, Valenti V, Rabbiosi D, et al. A systematic review on tracheostomy decannulation: a proposal of a quantitative semiquantitative clinical score. BMC Pulm Med 2014;14:201.

2. Budweiser S, Baur T, Jörres RA, Kollert F, Pfeifer M, Heinemann F. Predictors of successful decannulation using a tracheostomy retainer in patients with prolonged weaning and persisting respiratory failure. Respiration 2012;84(6):469-476.

3. Pandian V, Miller CR, Schiavi AJ, Yarmus L, Contractor A, Haut ER, et al. Utilization of a standardized tracheostomy capping and decannulation protocol to improve patient safety. Laryngoscope 2014; 124(8):1794-1800.

4. Esteban A, Anzueto A, Alía I, Gordo F, Apezteguía C, Pálizas F, et al. How is mechanical ventilation employed in the intensive care unit? An international utilization review. Am J Respir Crit Care Med 2000;161(5): 1450-1458

5. Freeman S. Care of adult patients with a temporary tracheostomy. Nurs Stand 2011;26(2):49-56.

6. Paul F. Tracheostomy care and management in general wards and community settings: literature review. Nurs Crit Care 2010;15(2): $76-85$. 


\section{Intratracheal Seal Disc in a Porcine Model}

7. Chadda K, Louis B, Benaissa L, Annane D, Gajdos P, Raphaël JC, et al. Physiological effects of decannulation in tracheostomized patients. Intensive Care Med 2002;28(12):1761-1767.

8. Martinez GH, Fernandez R, Casado MS, Cuena R, Lopez-Reina P, Zamora S, Luzon E. Tracheostomy tube in place at intensive care unit discharge is associated with increased ward mortality. Respir Care 2009;54(12):1644-1652.

9. O'Connor HH, White AC. Tracheostomy decannulation. Respir Care 2010;55(8):1076-1081.

10. McCool FD. Global physiology and pathophysiology of cough: ACCP evidence-based clinical practice guidelines. Chest 2006;129(1 Suppl): 48S-53S.

11. Christopher KL. Tracheostomy decannulation. Respir Care 2005; 50(4):538-541.

12. Hess DR, Altobelli NP. Tracheostomy tubes. Respir Care 2014; 59(6):956-971; discussion 971-953.

13. Hoffman B, Martin M, Brown BN, Bonassar LJ, Cheetham J. Biomechanical and biochemical characterization of porcine tracheal cartilage. Laryngoscope 2016;126(10):E325-E331

14. Mallick A, Bodenham A, Elliot S, Oram J. An investigation into the length of standard tracheostomy tubes in critical care patients. Anaesthesia 2008;63(3):302-306.
15. Mitchell RB, Hussey HM, Setzen G, Jacobs IN, Nussenbaum B, Dawson $\mathrm{C}$, et al. Clinical consensus statement: tracheostomy care. Otolaryngol Head Neck Surg 2013;148(1):6-20.

16. Ferrer M, Sellares J, Torres A. Noninvasive ventilation in withdrawal from mechanical ventilation. Semin Respir Crit Care Med 2014;35(4):507-518.

17. Burns KE, Adhikari NK, Keenan SP, Meade M. Use of non-invasive ventilation to wean critically ill adults off invasive ventilation: metaanalysis and systematic review. BMJ 2009;338:b1574.

18. Kopić J, Paradžik MT. Expanding the use of noninvasive ventilation during an epidemic. Disaster Med Public Health Prep 2014;8(4):310314.

19. Epstein SK. Late complications of tracheostomy. Respir Care 2005; 50(4):542-549.

20. Bhatia G, Abraham V, Louis L. Tracheal granulation as a cause of unrecognized airway narrowing. J Anaesthesiol Clin Pharmacol 2012; 28(2):235-238.

21. Ledl C, Mertl-Roetzer M. Tracheal and tracheostomal hypergranulation and related stenosis in long-term cannulated patients: does the tracheostomy procedure make a difference? Ann Otol Rhinol Laryngol 2009;118(12):876-880.

22. Heffner JE. Tracheostomy decannulation: marathons and finish lines. Crit Care 2008;12(2):128. 